\title{
Influence of Low-Level Laser Modification and Adhesive Application Mode on the Bonding Efficiency of Universal Adhesives to Er:YAG Laser- Ablated Dentin
}

\author{
Nesrine A. Elsahnn ${ }^{1,2}$, Hatem M. El-Damanhoury ${ }^{3 *^{(}}$, Dina W Elkassas ${ }^{(\oplus)}$ \\ ${ }^{1}$ Department of Restorative Dentistry, College of Dentistry, Ajman University, Ajamn, UAE \\ ${ }^{2}$ Department of Restorative Dentistry, Faculty of Oral and Dental Medicine, Cairo University, Cairo, Egypt \\ ${ }^{3}$ Department of Preventive and Restorative Dentistry, College of Dental Medicine, University of Sharjah, Sharjah, UAE \\ ${ }^{4}$ Department of Operative Dentistry, Misr International University, Cairo, Egypt
}

\section{*Correspondence to Hatem M. El-Damanhoury, BDS, MDS, PhD; \\ Associate Professor, Department of Preventive and Restorative Dentistry, \\ College of Dentistry, University of Sharjah, Sharjah, UAE. Office M28-129, College of Dentistry, University of Sharjah. P.O. Box: 27272 Sharjah, UAE, Tel: +971 6-505-7309, Fax : +971 6-558-5641, Email: hdamanhoury@sharjah. ac.ae}

Published online February 16 2021

\begin{abstract}
Introduction: Erbium laser ablation as a method of tooth preparation and conditioning has shown promising results. Although previous studies have adopted various combinations of different laser parameters and several dentin adhesive systems, very few have investigated combining high-level and low-level ER:YAG lasers with Universal adhesives. This study aimed to assess the impact of using low-energy irradiation on the surface micro-topography and shear bond strength (SBS) of universal adhesive (UA) to the erbium:yttrium-aluminum-garnet (Er:YAG) laser-ablated dentin substrate, bonded in etch-and-rinse or self-etch adhesive mode.

Methods: Eighty-seven extracted molars were sectioned to expose flat occlusal dentin surface; 60 teeth were divided equally into three groups according to the surface treatment; bur-cutting (B), Er:YAG high-energy laser cutting $\left(L_{1}-200 \mathrm{~mJ}, 20 \mathrm{~Hz}, 50 \mu \mathrm{s}\right.$ pulse), or $\mathrm{L}_{1}$ followed by low-energy laser modification $\left(\mathrm{L}_{1} / \mathrm{L}_{2}-80 \mathrm{~mJ}, 10 \mathrm{~Hz}, 50 \mu \mathrm{s}\right.$ pulse). Then each group was equally divided into two groups $(n=10)$ according to the mode of application of the universal adhesive; either etch-andrinse (ER) or self-etching (SE). The samples were subjected to thermocycling (5000 cycle between $5^{\circ} \mathrm{C}$ and $55^{\circ} \mathrm{C}$ ), and SBS was tested. Two-way ANOVA and Tukey post hoc test were used to analyze the results. The remaining 27 samples were used to investigate the effect of the treatment on the topography of the treated dentin surfaces using a scanning electron microscope (SEM).

Results: B/SE recorded the highest SBS $(25.48 \pm 2.6 \mathrm{MPa})$ followed by B/ER $(23.20 \pm 6.8 \mathrm{MPa})$ and $\mathrm{L}_{1} / \mathrm{L}_{2} / \mathrm{SE}(22.94 \pm 4.1 \mathrm{MPa})$ and with no statistically significant difference between these groups $(P$ $>0.05)$. The lowest SBS results $(P<0.05)$ were recorded for L1/SE $(12.22 \pm 3 \mathrm{MPa})$. No statistical differences were found between the SBS of $L_{1} / L_{2} / E R$ and $L_{1} / E R$ groups or between the $S B S$ of $L_{1} / L_{2} /$ $E R$ and $L_{1} / L_{2} / S E$ groups.

Conclusion: A subsequent treatment of the Er:YAG laser-ablated dentin with low-energy laser modification mode (LMM) enhances the SBS of the tested UA when applied in SE mode.

Keywords: Low-level laser, Er:YAG laser; Universal adhesives; Shear bond strength.
\end{abstract}

\section{Introduction}

The erbium:yttrium-aluminum-garnet (Er:YAG) laser has gained acceptance as an alternative to traditional mechanical instrumentation for cavity preparations, which owes to the coincidence between the emitted wavelength $(2.94 \mu \mathrm{m})$ and the strongest absorption band of water and $\mathrm{OH}$ - group in hydroxyapatite. ${ }^{1}$ The Er:YAG laser is well absorbed by enamel and dentin, allowing the thermo-mechanical ablation process to take place without causing thermal damage to the surrounding tissues. ${ }^{2}$

Topographical studies have shown that laser ablation with the erbium family results in a typically patterned surface with a microscopically rough microretentive aspect, open dentinal tubules, no smear layer production, and dentin surface sterilization. ${ }^{3}$ Despite the aforementioned appealing characteristics of the laser-ablated dentin substrate, the bonding process is considered a controversial issue. ${ }^{4}$ Several studies reported inferior bonding performance to laser-ablated dentin that was attributed to the thermo-mechanical ablation process, and what has been described as "laser-modified layer", which is characterized by complete melting and

Please cite this article as follows: Elsahn NA, El-Damanhoury HM, Elkassas DW. Influence of Low-Level Laser Modification and Adhesive Application Mode on the Bonding Efficiency of Universal Adhesives to Er:YAG Laser-Ablated Dentin. J Lasers Med Sci. 2021;12:e7. doi:10.34172/jlms.2021.07 
evaporation of the collagen network. ${ }^{5-7}$ Improper dentin hybridization may occur due to the surface irregularities of the ablated surface, leading to a non-uniform thickness of the adhesive layer, which may prevent even stress distribution at the bonded interface. ${ }^{8}$

The removal of the laser modified layer via the acidetching process was reported to diminish bonding efficiency, and the reported bond strength was significantly inferior to that of bur-prepared surfaces. ${ }^{5,7}$ Thus, other studies proposed the use of low-energy settings laser modification mode (LMM) following the use of high-energy laser-cutting mode (LCM), rendering the dentin substrate more receptive to the adhesion process. ${ }^{9-11}$ Although the bond strength of ER and SE adhesives to laser-ablated substrates was extensively tested in the literature, only a few studies evaluated the bonding performance of universal adhesives (UAs) to laser-ablated dentin using low or high powers. ${ }^{12-16}$ Universal dental adhesives are known as "multi-mode" adhesives that can be applied in etch-and-rinse (ER), self-etch (SE), or selective-etching modes, depending on the clinical situation. ${ }^{17}$ Mild UAs proved their ability to achieve a significantly strong bond to dentin, which owes to the presence of functional monomers as a principal ingredient, which plays a major and unique role in chemical adhesion to dentin. ${ }^{18,19}$

While few studies have reported no influence of the laser etching with low output power on the bond efficacy of some UA when used in either SE or ER modes, ${ }^{12-14}$ other studies have found that this effect is material-dependent. ${ }^{12}$ Furthermore, some studies have reported that LCM causes deterioration of the bond strength of UA. ${ }^{15,16}$ However, the impact of adding LMM and/ or the acid-etching step on the bond strength before the application of UA has scarcely been tackled in literature.

The pre-treatment of the dentin substrate highly influences the dentin adhesion and bond durability. Hence, this research was conducted to verify the effect of combining both laser energy modes on the dentin surface topography and the bond strength of a UA system, when used in either an ER mode or an SE mode. Bur-cut dentin was used as a control. The first null hypothesis tested was that the cutting mode (namely; bur cutting, LCM, and
LCM followed by LMM) has no effect on the bonding performance of the UA system when used in total-etch or self-etch modes. The second null hypothesis was that the use of LMM cannot omit the need for the conventional acid-etching step.

\section{Methods and Materials Sample Preparation}

A total of 87 caries-free extracted human mandibular molars were collected under a protocol approved by the research ethics committee of the University of Sharjah. The teeth were cleaned of calculus and soft tissues using an ultrasonic scaler, then stored at $4^{\circ} \mathrm{C}$ in a $1 \%$ chloramine- $\mathrm{T}$ solution and used within one month. The occlusal surfaces of all the teeth were trimmed until the complete removal of enamel, exposing the most superficial flat dentin surface under running water using a trimmer (Renfert MT plus, St. Charles, IL). The roots were fixed in dental stone (WhipMix, Louisville, KY) in cylindrical acrylic molds. Dentin surfaces were finished with a series of finishing discs of up to 600-grit (Soflex, $3 \mathrm{M}$ ESPE, St. Paul, MN) to create a uniform smear layer. Sixty specimens were selected and equally divided according to the different methods of surface treatments $(n=10)$. The information of the materials under investigation are presented in Table 1. Grouping of the specimens and description of the different treatments are represented in Table 2.

All the exposed dentin surfaces were marked with a permanent felt-tip marker. The ink marks in groups 1 and 2 were erased using a cylindrical bur (Diamond bur number 6881; Komet-Brasseler, Lemgo, Germany) with air-water coolant to create a standardized smear layer. The bur was discarded and replaced with a new one every five preparations.

In the remaining groups, the marks were erased using an Er:YAG laser (Fidelis AT, Fotona Medical Lasers, Ljubljana, Slovenia). The laser was operating with a non-contact handpiece (R02, Fotona) in a focused mode with a $0.9 \mathrm{~mm}$ beam spot size, a pulse duration of $50 \mu \mathrm{s}$ super short pulse, under air/water spray of $80 \mathrm{~mL} / \mathrm{mm}$ water and $40 \mathrm{~mL} / \mathrm{mm}$ air. The irradiation parameters of LCM were fixed at $200 \mathrm{~mJ} /$ pulse, $20 \mathrm{~Hz}$, and $4 \mathrm{~W}$. The

Table 1. Names, Composition, Manufacturer and Lot Number of the Materials Under Investigation

\begin{tabular}{|c|c|c|c|}
\hline Material (Category) & Composition & Manufacturer & Lot Number \\
\hline $\begin{array}{l}\text { Single bond } \\
\text { universal }\end{array}$ & $\begin{array}{l}\text { MDP Phosphate Monomer, Dimethacrylate resins, HEMA, Vitrebond }{ }^{\top M} \\
\text { Copolymer, filler, ethanol, water, initiators, silane }\end{array}$ & 3M ESPE, St. Paul, MN, USA & 4625656 \\
\hline Scotchbond (acid etchant) & $35 \%$ phosphoric acid gel, silica thickener & 3M ESPE, St. Paul, MN, USA & 666184 \\
\hline $\begin{array}{l}\text { Filtek Z250 XT } \\
\text { (Nano-Hybrid Universal Resin } \\
\text { composite) }\end{array}$ & $\begin{array}{l}\text { 55-65 wt \% Water, 30-40 wt \% Phosphoric Acid, 5-10 wt } \% \text { Synthetic } \\
\text { Amorphous Silica, Surface Modified Zerconia/Silica (0.1-10 microns), } 20 \\
\text { nm Surface Modified Silica Particles, } 81.8 \text { wt } \% \text { Inorganic Filler (67.8 vol.\%), } \\
\text { Bis-GMA, UDMA, Bis-EMA, PEGDMA, TEGDMA. }\end{array}$ & 3M ESPE, St. Paul, MN, USA & N983005 \\
\hline
\end{tabular}

MDP, methacryloyloxydecyl dihydrogen phosphate; HEMA, Hydroxyethyl methacrylate; Bis-GMA, Bisphenol A diglycidyl methacrylate; UDMA, urethane dimethacrylate; Bis-EMA, ethoxylated bisphenol A dimethacrylate; PEGDMA, Poly (ethylene glycol) dimethacrylate; TEGDMA, triethylene glycol dimethacrylate 
distance between the laser handpiece and tooth surface was standardized using a customized holder that was set to $7 \mathrm{~mm}$, which allowed for free horizontal movement of the stone block with the embedded tooth. Afterward, the specimens in groups 5 and 6 received LMM with the second irradiation of Er:YAG laser under $80 \mathrm{~mJ} /$ pulse, 10 $\mathrm{Hz}$, and $0.8 \mathrm{~W}$.

For the etch-and-rinse mode groups (groups 1, 3 and 5), 35\% phosphoric acid gel was used to etch the prepared teeth surfaces for 15 seconds. The specimens were rinsed with distilled water for 10 seconds and then dried with micro-sponges. Afterward, single bond universal adhesive (SU) was applied to two successive layers, each rubbed against the dentin surface for 20 seconds using a micro brush, followed by drying with a gentle stream of air for 5 seconds, cured for 20 seconds using an LED light-curing unit (Mini LED, Acteon, Germany) in a standard mode with irradiance output of $1250 \pm 20 \mathrm{~mW} / \mathrm{cm}^{2}$. In the selfetch mode groups (groups 2, 4 and 6), SU was applied and cured, following the same protocol used in the previous etch-and-rinse group, directly on the dentin surfaces without acid-etching.

Cylindrical Teflon molds with an inner diameter of 2 $\mathrm{mm}$ and a depth of $2 \mathrm{~mm}$ were secured to the specimen using a special holder. Filtek Z250 XT, 3M ESPE resin composite, was packed into the cylindrical cavity and polymerized for 20 seconds. A digital radiometer (Cure Rite, Dentsply Caulk) was used to verify the light intensity of the LCU before the polymerization of each specimen. The Teflon molds were removed carefully, leaving cylindrical composite rods bonded to the dentin specimens.

\section{Storage and Thermal Aging}

An incubator with a $37^{\circ} \mathrm{C}$ temperature was used to store the specimens for 24 hours in distilled water, and then all the specimens were thermo-cycled (Thermocycler THE1200, SD Mechatronik GMBH) between 5 and $55^{\circ} \mathrm{C}$ with 30-second dwell times for 5000 cycles.

\section{Shear Bond Strength Testing}

A table-top testing machine (SBS tester, Bisco Inc., Schaumburg, IL, USA) was used to test the shear bond strength (SBS) of the specimens. Shear forces were applied at the bonded interface with a semicircular metal attachment until failure and running at a crosshead speed of $1.0 \mathrm{~mm} / \mathrm{min}$. To calculate the bond strength in $\mathrm{MPa}$, the force at the time of failure $(\mathrm{N})$ was recorded and divided by the surface area of the bonded interface.

SBS results were analyzed using a two-way analysis of variance (ANOVA) test, and to compare between the tested groups, a Tukey post hoc test was used. A group was considered significantly different at $P<0.05$. All the statistical tests were done using SPSS software (SPSS version 20.0, SPSS Inc., Chicago IL).

A stereomicroscope (Nilson SMZ-10, Japan) at $\times 25$ magnification was used to examine the fractured specimens and determine the mode of failure. Failure modes were classified as adhesive, where the failure occurred between the adhesive and the dentin, cohesive in dentin or cohesive in the composite or mixed, including a combination of more than one type of failure. The percentage of each failure mode within the group was calculated.

\section{Micromorphological Analysis}

The remaining twenty-seven dentin specimens were divided into nine groups $(n=3)$, representing the nine different treatments tested. Grouping of the samples for micromorphological analysis and description of the various treatments is described in Table 3.

In SE groups, the light-curing step of SU was skipped. Nevertheless, after the application of SU, all SE group specimens were cleaned in an acetone bath in an ultrasonic cleaner for 5 minutes to remove any crystals and other residues from the UA, then the teeth were left to air dry. Sputter-coating of the specimens was done with Carbon for 10 seconds (EMS 7620 Mini Sputter Coater, Hatfield, PA). Micrographs of the prepared samples were taken at different magnifications up to $\times 2000$, using a scanning electron microscope (SEM) (JSM 5310LV, JEOL Inc., Tokyo, Japan), running at $10 \mathrm{kV}$ accelerating voltage and $20 \mathrm{~mm}$ working distance.

\section{Results}

The results of the SBS test (values and standard deviations in $\mathrm{MPa}$ ) and failure modes of the tested groups are presented in Table 4. The two-way ANOVA analysis

Table 2. Grouping of the Specimens for the Shear Bond Strength Test

\begin{tabular}{ll}
\hline Group & Description \\
\hline Group $1(\mathrm{~B} / \mathrm{ER}):$ & High-speed bur cutting, acid-etching, universal resin adhesive (etch-and-rinse mode) \\
Group $2(\mathrm{~B} / \mathrm{SE}):$ & High-speed bur cutting, universal resin adhesive (self-etch mode) \\
Group $3\left(\mathrm{~L}_{1} / \mathrm{ER}\right):$ & Er:YAG laser preparation cutting mode $\left(\mathrm{L}_{1}\right)$, no modification, acid-etching, universal resin adhesive (etch-and-rinse mode) \\
Group $4\left(\mathrm{~L}_{1} / \mathrm{SE}\right):$ & Er:YAG laser preparation cutting mode $\left(\mathrm{L}_{1}\right)$, no modification, universal resin adhesive (self-etch mode) \\
Group $5\left(\mathrm{~L}_{1} / \mathrm{L}_{2} / \mathrm{ER}\right):$ & $\begin{array}{l}\text { Er:YAG laser preparation cutting mode }\left(\mathrm{L}_{1}\right) \text {, laser modification mode }\left(\mathrm{L}_{2}\right) \text {, acid-etching, and universal resin adhesive (etch-and-rinse } \\
\text { mode) }\end{array}$ \\
\hline
\end{tabular}


Table 3. Grouping of the Specimens for the Micromorghological Analysis

\begin{tabular}{|c|c|c|}
\hline Group & & Description \\
\hline \multirow{3}{*}{ Bur } & B & High-speed bur cutting, then rinsing with no further treatment. \\
\hline & $\mathrm{B} / \mathrm{ER}$ & High-speed bur cutting, acid-etching, then rinsing. \\
\hline & $\mathrm{B} / \mathrm{SE}$ & High-speed bur cutting, uncured universal adhesive application, then ultrasonic cleaning in an acetone bath. \\
\hline \multirow{3}{*}{ LCM } & $\mathrm{L}_{1}$ & Er:YAG laser preparation cutting mode $\left(\mathrm{L}_{1}\right)$, then rinsing with no further treatment. \\
\hline & $L_{1} E R$ & Er:YAG laser preparation cutting mode $\left(\mathrm{L}_{1}\right)$, acid-etching, then rinsing. \\
\hline & $\mathrm{L}_{1} \mathrm{SE}$ & Er:YAG laser preparation cutting mode $\left(\mathrm{L}_{1}\right)$, uncured universal adhesive application, then ultrasonic cleaning in an acetone bath. \\
\hline \multirow{3}{*}{ LCM/ LMM } & $\mathrm{L}_{1} / \mathrm{L}_{2}$ & Er:YAG laser preparation cutting mode $\left(\mathrm{L}_{1}\right)$, laser modification mode $\left(\mathrm{L}_{2}\right)$, then rinsing with no further treatment. \\
\hline & $\mathrm{L}_{1} / \mathrm{L}_{2} / \mathrm{ER}$ & Er:YAG laser preparation cutting mode $\left(\mathrm{L}_{1}\right)$, laser modification mode $\left(\mathrm{L}_{2}\right)$, acid-etching, then rinsing. \\
\hline & $\mathrm{L}_{1} / \mathrm{L}_{2} / \mathrm{SE}$ & $\begin{array}{l}\text { Er:YAG laser preparation cutting mode }\left(\mathrm{L}_{1}\right) \text {, laser modification mode }\left(\mathrm{L}_{2}\right) \text {, uncured universal adhesive application, then ultrasonic } \\
\text { cleaning in an acetone bath. }\end{array}$ \\
\hline
\end{tabular}

Table 4. Mean Shear Bond Strength Values in MPa and the Percentage of Failure Modes of All Tested Groups

\begin{tabular}{|c|c|c|c|c|c|}
\hline \multirow{2}{*}{ Group } & \multirow{2}{*}{ Shear Bond Strength (MPa) } & \multicolumn{4}{|c|}{ Mode of Failure (\%) } \\
\hline & & Adhesive & Mixed & Cohesive/ Dentin & Cohesive/ Resin \\
\hline Group 1 (B/ER): & $23.20 \pm 6.8^{\mathrm{a}}$ & 40 & 60 & 0 & 0 \\
\hline Group 2 (B/SE): & $25.48 \pm 2.6^{\mathrm{a}}$ & 80 & 20 & 0 & 0 \\
\hline Group $3\left(\mathrm{~L}_{1} / \mathrm{ER}\right)$ : & $17.73 \pm 2.9^{c}$ & 80 & 20 & 0 & 0 \\
\hline Group $4\left(\mathrm{~L}_{1} / \mathrm{SE}\right)$ : & $12.22 \pm 3^{\mathrm{d}}$ & 70 & 20 & 0 & 0 \\
\hline Group $5\left(\mathrm{~L}_{1} / \mathrm{L}_{2} / \mathrm{ER}\right)$ : & $19.18 \pm 3.2^{b c}$ & 60 & 40 & 0 & 0 \\
\hline Group $7\left(\mathrm{~L}_{1} / \mathrm{L}_{2} / \mathrm{SE}\right)$ : & $22.94 \pm 4.1^{\mathrm{ab}}$ & 20 & 80 & 0 & 0 \\
\hline
\end{tabular}

Note. The same superscript letters show mean values with no statistically significant difference $(P<0.05)$

revealed that both variables, method of cutting and UA application mode, had a significant effect on the SBS of the tested groups $(P<0.001)$. Moreover, the results revealed that the LCM of Er:YAG had a significant negative impact on the SBS of the tested UA regardless of the mode of SU application. However, the acid-etching step after laser ablation with LCM significantly increased the SBS from $12.22 \pm 3 \mathrm{MPa}$ in the L1/SE group to $17.73 \pm 2.9 \mathrm{MPa}$ in the L1/ER group. Nevertheless, the recorded bond strength value in the L1/ER group was considerably lower than those of $\mathrm{B} / \mathrm{ER}$ and $\mathrm{B} / \mathrm{SE}$ groups $(P<0.05)$. The application of LMM following LCM significantly raised the SBS value exclusively in the L1/L2/SE group in comparison to the L1/SE group $(P<0.05)$. On the other hand, the SU application mode did not affect the SBS of bur-prepared groups, groups 1 and 2, or laser-cut laser-modified groups, groups 5 and $6(P>0.05)$. However, omitting the acid-etching step in the L1/L2/SE group resulted in the SBS of $22.94 \pm 4.1 \mathrm{MPa}$, which was comparable to the SBS of $\mathrm{B} / \mathrm{ER}$ and $\mathrm{B} / \mathrm{SE}$ groups.

The lowest percentage of the adhesive mode of failure was present in the L1/L2/SE group (20\%) followed by the B/ER group (40\%). On the contrary, the adhesive mode was the predominant mode of failure in groups B/SE, L1/ ER, L1/SE and L1/L2/ER.

The SEM topographical analysis of the dentin
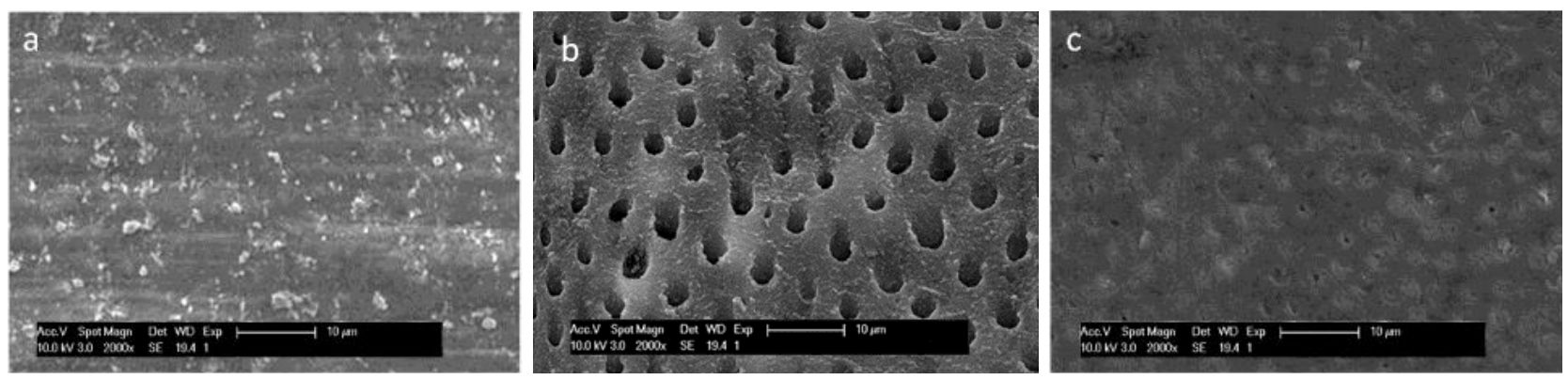

Figure 1. Microphotographs for Bur groups, showing the bur-cut dentin surfaces after a) No treatment (group B) with a Smear layer covering the dentin surface, b) Acid etching (group B/E), showing a flat surface with no smear layer and widely open funnel-like dentinal tubules, and c) Universal adhesive (group B/SE), showing a smear layer covering dentin surface with smear plugs obliterating the dentinal tubules. 
specimens prepared with a carbide bur showed a relatively homogenous surface with a smear layer covering the dentin surface, and blocking the tubules with bur striations was evident (Figure 1a). Phosphoric acid-etching completely removed the smear layer, and the dentinal tubules apertures were visible (Figure $1 b$ ). The use of the self-etch mode of SU led to partial elimination of the smear layer, with the partial opening of a little number of dentinal tubules (Figure 1c).

The dentin surfaces treated with LCM (Figure 2a) were rough, irregular, scaly, and smear-free. Peritubular dentin was protruded, which could be depicted as having a cufflike appearance. Acid etching of the laser-ablated dentin substrate (Group L1/ER) led to a severely eroded dentin surface, with deep demineralization of intertubular dentin, and the remnants of the peritubular dentin were protruding from the dissolved dentin. (Figure $2 b$ ). With the self-etch mode (L1/SE), the surface was relatively scaly and irregular (Figure 2c), but to a lesser extent, in comparison to group L1. The tubule apertures were smooth, rounded, and smaller in diameter than group L1/ ER.

Laser modification of the laser-ablated dentin substrate (group L1/L2, Figure 3a) also showed an irregular, scaly appearance but was less evident compared to L1 (Figure 2a) with an apparent reduction in the sharp edges. Acid etching of this group (L1/L2/E) led to the removal of the irregular scaly layer and an increase in the opening of the dentinal tubule apertures; however, their margins were also rough and corrugated. With the self-etch mode (L1/ L2/SE, Figure 3c), the surface was relatively smooth, with open dentinal tubules and smoother apertures.

\section{Discussion}

The aim of this research was to study the effect of using a low-energy laser and acid-etching as a dentin conditioning method before the application of UA on the bonding efficacy of a nano-hybrid resin composite bonded to the Er:YAG laser-ablated dentin substrate, and a bur-cut dentin group was used as a control. The results revealed that the method of dentin surface preparation significantly affected the bonding performance of the UA under investigation $(P<0.05)$. Accordingly, the first null hypothesis was rejected. The SBS of the L1/L2/SE group was statistically similar to that of the $\mathrm{L}_{1} / \mathrm{L}_{2} / \mathrm{ER}$ group $(P>0.05)$. On the contrary, acid-etching of the laserablated dentin surfaces that received a second irradiance with LMM dramatically decreased the bond strength in comparison to the control group. Therefore, the second null hypothesis was also rejected.
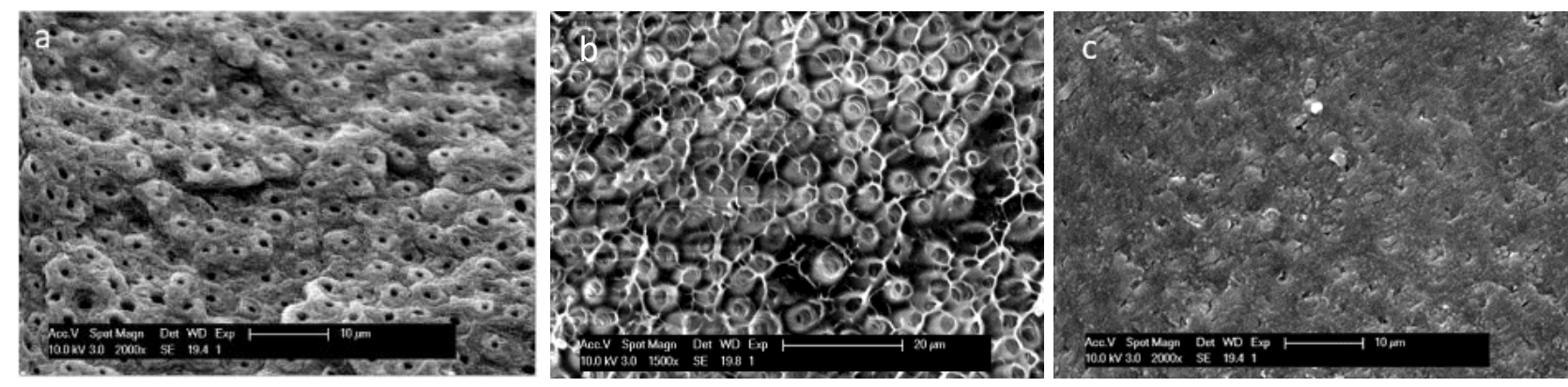

Figure 2. Microphotographs for LCM Groups. (a) laser-ablated dentin substrates after no treatment (group $\mathrm{L}_{1}$ ), displaying irregular surface with no smear layer, presence of areas with depressed intertubular dentin and no collagen matrix is exposed, (b) laser-ablated dentin substrates acid-etching (group $\mathrm{L}_{1 /} \mathrm{ER}$ ), showing severely eroded dentin surface with deep demineralization of intertubular dentin, and the reminants of the pritubular dentin is protruding from the dissolved dentin. (c) laser-ablated dentin substrates after application of universal adhesive (group $\mathrm{L}_{1}, \mathrm{SE}$ ), showing constricted dentinal tubules with the preservation of peritubular dentin.
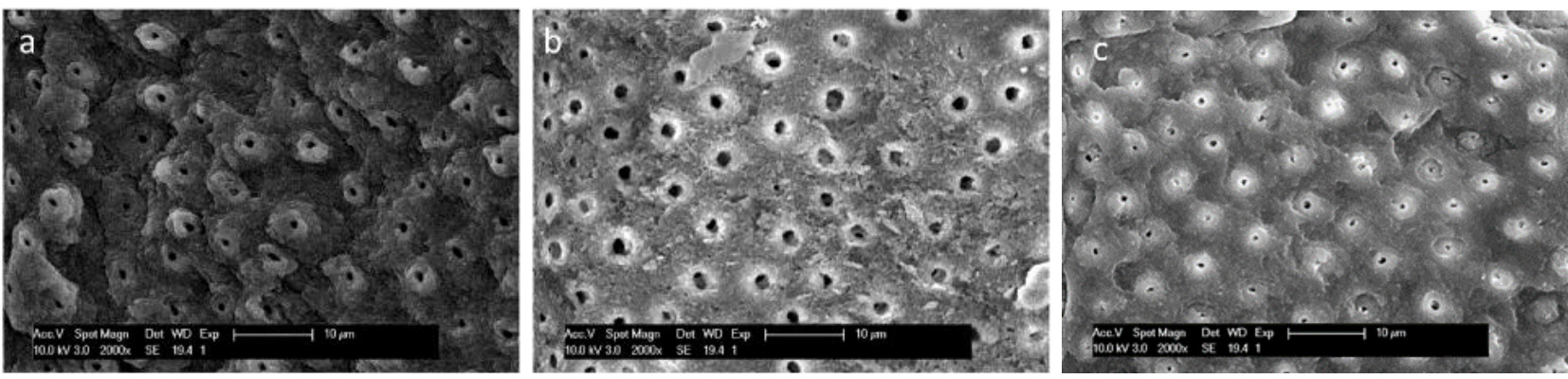

Figure 3. Microphotographs for LCM/LMM groups, showing the laser-ablated/ laser-modified dentin substrates after (a) No treatment (group $L_{1} / L_{2}$ ), revealing more regular surface with protrusion of peritubular dentin (cuff-like appearance), (b) Acid Etching (group $L_{1} / L_{2} / E R$ ), with a flatter rough surface, constricted dentinal tubules orifices, and evidence of intertubular dentin etching while peritubular dentin is preserved, and (c) Universal adhesive (group $\mathrm{L}_{1} / \mathrm{L}_{2} / \mathrm{SE}$ ), showing flat and smooth surface with the partial opening of dentinal tubules and preservation of peritubular dentin. 
The latest innovation in adhesive systems was the release of multi-mode or UAs, being more flexible systems that allow the dentist to determine which adhesive approach to use: ER or SE. ${ }^{17}$ In the present study, the highest SBS values were observed in the bur-prepared groups, when bonded with either ER or SE mode of SU. Moreover, the SBS of the L1/L2/SE group was statistically comparable to the bur-prepared groups $(P>0.05)$. In contrast, there was a significant drop in the SBS of composite bonded to dentin surfaces ablated with LCM $(P<0.05)$.

The SBS results of bur-prepared groups are in agreement with the outcomes of most of the in vitro studies that assessed the bonding performance of UAs, which concluded that the bonding approach or etching mode did not affect the bonding of mild UA to dentin. ${ }^{20-23}$ Moreover, Kawazu et al revealed that SU did not show any significant decrease in SBS from the baseline under any degradation condition. ${ }^{24} \mathrm{SU}$ is a mild $\mathrm{UA}(\mathrm{pH} \approx 2.7)$ that contains MDP monomer, and the superior performance of this adhesive is attributed to the formation of a firm nanolayer around dentinal hydroxyapatites..$^{25,26}$ According to Perdigão et al, the unique combination of MDP monomer and polyalkenoic acid copolymer (Vitrebond copolymer) in SU improves the chemical bonding to dentin. ${ }^{27}$ The limited surface-decalcification effect of the acidic monomers will allow for an additional micromechanical bond by encapsulating the decalcified collagen fibers as described by the adhesion/decalcification or ADConcept. ${ }^{28}$

Although acid-etching of bur-prepared dentin can remove the weak, porous inhomogeneous physical barrier for resin infiltration known as the smear layer (Figure 1b) and promote deeper impregnation of UA monomers, which are factors that contribute to higher bonding efficacy, Pashly et al hypothesized that prior phosphoric acid-etching might compromise the chemical bonding of MDP monomer to hydroxyapatites due to the reduction of the amount of calcium and phosphate ions. ${ }^{29}$ This postulation might explain the statistical similarity of SBS between $\mathrm{B} / \mathrm{SE}$ and $\mathrm{B} / \mathrm{ER}$ groups $(P>0.05)$.

SEM results revealed that the Er:YAG cutting mode using high-power energy altered the dentin surface topography producing a flaking, asymmetrical, and rough dentin substrate with the absence of the smear layer with patent dentinal tubule openings (Figure 2a). The peritubular dentin projected from the encircling intertubular dentin, having a cuff-like appearance. This characteristic appearance of laser-cut dentin can be clarified by recognizing the development of watermediated ablation. Since intertubular dentin holds more moisture and fewer minerals in comparison to peritubular dentin, the intertubular dentin is affected by the laser more than the peritubular dentin. The highly mineralized peritubular dentine forms a cuff around the tubule orifices ${ }^{30}$ and increases calcium and phosphorus in Er:YAG laser-ablated dentin surfaces. ${ }^{31}$
The resultant irregular smear-free and the highly mineralized laser-ablated substrate should have facilitated the micro-mechanical and chemical interaction of SU in the SE mode and produced a stronger bond and a more stable hybrid layer in comparison to bur-cut dentin. Unluckily, the mean SBS of the L1/SE group was significantly lower than that of the B/ER and B/SE groups. The inferior performance of SE adhesives to laser-ablated dentin was reported by Trevelin et al, who examined the laser altered layer under the transmission electron microscopy when the dentin surface was ablated using the same LCM parameters utilized in the current study; they observed a thick altered zone (4.5- $\mu$ m thick), where carbonization takes place in the superficial layer and the subsurface layer is composed of molten dentin with loss of interfibrillar spaces between the fused collagen fibers. ${ }^{32}$ The expected limited resin infiltration within this altered substrate was believed to interfere with adequate hybridization ${ }^{33}$; therefore, the inferior bond strength to laser-irradiated dentin was attributed to the presence of this thermally denatured layer and the cracks seen in denatured dentin under the hybrid layer., ${ }^{74-37}$ Furthermore, the scaly surface observed in Figure 2a might have induced areas of stress concentration, jeopardizing the durability of the bond formed in the L1/ SE group. ${ }^{8}$

Most of the previous studies which failed to obtain a satisfactory bond strength to dentin after high laser outputs suggested acid-etching of laser-ablated dentin prior to the application of various self-etch adhesives, claiming that acid-etching might remove or reduce the thickness of the thermally affected surface and subsurface layer and enhance resin diffusion. ${ }^{10,38}$ The conflicting results of these studies might be attributed to the technique sensitivity associated with the total etching technique, which is highly influenced by the time of etching, degree of wetness/dryness of the dentin surface after etching and rensing, and the samples' storage conditions before testing. ${ }^{39}$ According to the results of the current study, acid-etching significantly improved the SBS of SU (group L1/ER) after LCM. In addition, the recorded bond strength was higher than that of the L1/SE group. However, this improvement cannot be considered satisfactory in comparison to bur-prepared groups. The results of our study are in agreement with several authors, ${ }^{5,40,41}$ who attributed their results to the higher resistance of laser-ablated dentin to acid-etching. On the contrary, other studies found no statistically significant difference between bur-cut/acid-etched and laser-ablated/acid-etched dentin substrates. ${ }^{42,43}$

Another explanation of the superior SBS results of the B/ER group compared to the L1/ER group can be credited to the presence of the smear layer on bur-prepared dentin surfaces that might neutralize the strong phosphoric acid and limit the depth of demineralization to few microns. On the other hand, we can postulate that acid-etching 
of the laser-cut smear-free surface might have destroyed the dentin architecture, and even the highly mineralized peritubular dentin was severely eroded, which was easily noted in the SEM analysis (Figures $2 \mathrm{~b}$ and $3 \mathrm{~b}$ ). The risk of age-dependent hydrolytic and enzymatic structural degradation of the unsupported collagen fibers would substantially increase, especially in areas of discrepancy resulted from incomplete monomer infiltration into the deeply demineralized dentin substrate. This deteriorating effect was significantly intensified by the thermo-cycling aging, which consequently allowed the failure of this group to occur at a much lower value than bur-prepared groups. ${ }^{44,45}$

Moreover, the increase in the opening of the dentinal tubules apertures with the characteristic moth-eaten appearance observed in Figure $2 \mathrm{~b}$ might have facilitated the displacement of the resin tags. These possibilities might explain the predominance of adhesive failure in the L1/ER group. Mirzaee et al found that after thermocycling for 1500 cycles, the SE mode of SU exhibited a similar SBS to another etch-and-rinse adhesive in the dentin groups ablated with $3 \mathrm{~W}$ Er:YAG laser output power. Still, the bond strength was significantly lower than that in the bur-prepared groups. ${ }^{15}$ In a recent study, Shadman et al found a similar deterioration in the SBS of SU, used in both self-etch and etch-and rinse-modes, to dentin in Er,Cr:YSGG lased dentin groups using $4 \mathrm{~W}$ and $5 \mathrm{~W}$ output powers than bur-prepared groups, even after 500 thermocycles. ${ }^{16}$ Although the results of these two recent studies are in accordance with the SBS of our results, none of these investigations examined the effect of using LMM after LCM.

LMM parameters in this study were selected following the previous studies that reported that laser conditioning using these parameters might help to eliminate the thermally altered layer or at least reduced its thickness that can significantly improve resin infiltration and the TBS. ${ }^{11}$ The SEM analysis of our study revealed that the addition of LMM reduced surface irregularities and sharp edges (Figure $3 \mathrm{a}$ and $3 \mathrm{c}$ ), allowing for better stress distribution at the tooth restoration interface, as described by Delme and De Moor. ${ }^{9}$ At the same time, the typical micro crater-like appearance of laser-cut dentin surfaces was preserved, and dentinal tubules orifices appeared more constricted and maybe more retentive. The SEM images of the LCM/LMM groups showed highly mineralized well preserved peritubular dentin. According to Bahrami et al, the low-power modification mode at $80 \mathrm{~mJ} /$ pulse and $10 \mathrm{~Hz}$ frequency after high-energy laser settings might also have significantly reduced the deteriorating effect of the thermally affected layer. ${ }^{11}$ The resultant surface alteration seems to be the optimum condition to enhance the bonding durability of SU, as revealed by the SBS value of the L1/L2/SE group, which was statistically similar to the $\mathrm{B} / \mathrm{ER}$ and $\mathrm{B} / \mathrm{SE}$ groups and significantly higher than the L1/ER and L1/SE groups after thermocycling.
The results of the current study are also in agreement with those reported by Guven and Aktoren, who found that LMM following laser cutting resulted in superior bonding performance of self-etch adhesives. The authors suggested that LMM is more efficient than acid-etching in rendering the ablated dentin substrate more receptive to resin bonding. ${ }^{46}$

In contrast, Chen et al reported no difference between phosphoric acid and low-fluence Er:YAG laser irradiation in their positive effect on the bond strength. ${ }^{10}$ Meanwhile, Yazici et al revealed that acid-etching after 3 W Er,Cr:YSGG laser ablation significantly enhanced the SBS of SU while the additional laser etching step with 1.5 W laser etching did not. The recorded SBS in the former study after the laser etching was statistically similar to the bond achieved with the SE mode of SU following 3W laser ablation. The contradiction of these results can be attributed to the difference in laser type and parameters used. ${ }^{15,16}$ However, the influence of LMM dentin surface modification after laser cutting on the bond strength and bond durability was not previously addressed in the literature.

The direct application of SU in the SE mode after surface modification with LMM yielded a satisfactory and durable SBS, comparable to bur-prepared surfaces with the highest detected percentage of the mixed mode of failure. While the results of the current study revealed no statistically significant difference between the L1/L2/ ER and L1/L2/SE groups, the mean SBS value of the L1/ L2/ER group was significantly lower than the mean SBS of both $\mathrm{B} / \mathrm{ER}$ and $\mathrm{B} / \mathrm{SE}$ groups. A higher percentage of adhesive failure was recorded for the L1/L2/ER group in comparison to the L1/L2/SE group, denoting that acidetching after LMM is not recommended.

The findings of this research can be partially attributed to the ability of the UA to eliminate the surface irregularities that remained after the modification step, allowing more uniformity of stress transfer at the tooth restoration interface (Figures 3a and 3c). ${ }^{9}$ Additionally, the relatively high $\mathrm{pH}$ of the tested $\mathrm{UA}(\mathrm{pH} \approx 2.7)$ makes it fall in the mildly acidic category, ${ }^{47}$ which was capable of altering the lased/modified dentin substrate and the degree of surface mineralization required for chemical adhesion with SU functional monomers, without damaging the dentin structure.

The limitations of this study are the use of only one type of UA and the use of Er:YAG with only two laser setting parameters. The authors assume that the use of several UAs with different compositions or other Erbium lasers with different parameters may result in alternative outcomes and are recommended for further investigation.

\section{Conclusion}

Under the limitations of the present study, it can be concluded that the application of low-Power ER:YAG laser irradiation parameters following high-Power laser 
irradiation parameters can positively alter the surface topography and enhance the bonding performance of the UA to dentin. On the other hand, although acid-etching increased the SBS of SU adhesive to dentin substrates ablated with a high-power Er:YAG laser, preconditioning the ablated surface with LMM made the step of acidetching unnecessary. The application of SU in the selfetch mode can yield a satisfactory and durable bond to laser-ablated/laser-conditioned dentin.

\section{Ethical Considerations}

This study was approved by the research ethics committee of the University of Sharjah (Approval code \# REC-1810-09-03-S).

\section{Conflict of Interests}

The authors of this manuscript declare no conflict of interest.

\section{References}

1. Firat E, Gurgan S, Gutknecht N. Microtensile bond strength of an etch-and-rinse adhesive to enamel and dentin after Er:YAG laser pretreatment with different pulse durations. Lasers Med Sci. 2012;27(1):15-21. doi: 10.1007/s10103010-0830-9.

2. Kilinc E, Roshkind DM, Antonson SA, Antonson DE, Hardigan PC, Siegel SC, et al. Thermal safety of Er:YAG and Er,Cr:YSGG lasers in hard tissue removal. Photomed Laser Surg. 2009;27(4):565-70. doi: 10.1089/pho.2008.2335.

3. Harashima T, Kinoshita JI, Kimura Y, Brugnera A, Zanin F, Pecora JD, et al. Morphological comparative study on ablation of dental hard tissues at cavity preparation by Er:YAG and Er,Cr:YSGG lasers. Photomed Laser Surg. 2005;23(1):52-5. doi: 10.1089/pho.2005.23.52.

4. Lopes RM, Trevelin LT, da Cunha SR, de Oliveira RF, de Andrade Salgado DM, de Freitas PM, et al. Dental adhesion to Erbium-lased tooth structure: a review of the literature. Photomed Laser Surg. 2015;33(8):393-403. doi: 10.1089/ pho.2015.3892.

5. Ceballos L, Toledano M, Osorio R, Tay FR, Marshall GW. Bonding to Er-YAG-laser-treated dentin. J Dent Res. 2002;81(2):119-22. doi: 10.1177/0810119.

6. Botta SB, da Ana PA, Zezell DM, Powers JM, Matos AB. Adhesion after erbium, chromium:yttrium-scandiumgallium-garnet laser application at three different irradiation conditions. Lasers Med Sci. 2009;24(1):67-73. doi: 10.1007/s10103-007-0521-3.

7. Ramos TM, Ramos-Oliveira TM, Moretto SG, de Freitas PM, Esteves-Oliveira M, de Paula Eduardo C. Microtensile bond strength analysis of adhesive systems to Er:YAG and Er,Cr:YSGG laser-treated dentin. Lasers Med Sci. 2014;29(2):565-73. doi: 10.1007/s10103-012-1261-6.

8. Cardoso MV, Coutinho E, Ermis RB, Poitevin A, Van Landuyt K, De Munck J, et al. Influence of dentin cavity surface finishing on micro-tensile bond strength of adhesives. Dent Mater. 2008;24(4):492-501. doi: 10.1016/j. dental.2007.04.011.

9. Delme KI, De Moor RJ. Scanning electron microscopic evaluation of enamel and dentin surfaces after Er:YAG laser preparation and laser conditioning. Photomed Laser Surg. 2007;25(5):393-401. doi: 10.1089/pho.2006.2069.

10. Chen ML, Ding JF, He YJ, Chen Y, Jiang QZ. Effect of pretreatment on Er:YAG laser-irradiated dentin. Lasers Med Sci. 2015;30(2):753-9. doi: 10.1007/s10103-013-14151.

11. Bahrami B, Askari N, Tielemans M, Heysselaer D, Lamard L, Peremans A, et al. Effect of low fluency dentin conditioning on tensile bond strength of composite bonded to Er:YAG laser-prepared dentin: a preliminary study. Lasers Med Sci. 2011;26(2):187-91. doi: 10.1007/s10103-010-0767-z.

12. Ayar MK, Erdermir F. Bonding strength of universal adhesives to Er,Cr:YSGG laser-irradiated dentin. Niger J Clin Pract. 2018;21(1):93-98.

13. Buyukhatipoglu I, Ozsevik AS, Secilmis A, Usumez A. Effect of dentin laser irradiation at different pulse settings on microtensile bond strength of flowable resin. Dent Mater J. 2016;35(1):82-8. doi: 10.4012/dmj.2015-090.

14. Yazici AR, Karaman E, Tuncer D, Berk G, Ertan A. Effect of an Er,Cr:YSGG laser preparation on dentin bond strength of a universal adhesive. J Adhes Sci Technol. 2016;30(22):247784. doi: 10.1080/01694243.2016.1184812.

15. Mirzaee M, Fasih P, Yasini E, Chiniforush N, Kharrazifard MJ, Rafiezadeh S, et al. Shear bond strength of nanocomposites to dentin substrate treated with Er:YAG laser followed by two different bonding systems. J Islam Dent Assoc Iran. 2017;29(2):51-7. doi: 10.30699/ jidai.29.2.51.

16. Shadman N, Farzin Ebrahimi S, Amanpour S, Mehdizadeh S. Shear bond strength of a multi-mode adhesive to burcut and Er,Cr:YSGG lased dentin in different output powers. J Dent (Shiraz). 2019;20(2):118-23. doi: 10.30476/ DENTJODS.2019.44922.

17. da Rosa WL, Piva E, Silva AF. Bond strength of universal adhesives: a systematic review and meta-analysis. J Dent. 2015;43(7):765-76. doi: 10.1016/j.jdent.2015.04.003.

18. Cuevas-Suárez CE, da Rosa WLO, Lund RG, da Silva AF, Piva E. Bonding performance of universal adhesives: an updated systematic review and meta-analysis. J Adhes Dent. 2019;21(1):7-26. doi: 10.3290/j.jad.a41975.

19. Elkaffas AA, Hamama HHH, Mahmoud SH. Do universal adhesives promote bonding to dentin? A systematic review and meta-analysis. Restor Dent Endod. 2018;43(3):e29. doi: 10.5395/rde.2018.43.e29.

20. Takamizawa T, Barkmeier WW, Tsujimoto A, Berry TP, Watanabe $\mathrm{H}$, Erickson RL, et al. Influence of different etching modes on bond strength and fatigue strength to dentin using universal adhesive systems. Dent Mater. 2016;32(2):e9-21. doi: 10.1016/j.dental.2015.11.005.

21. Wagner A, Wendler M, Petschelt A, Belli R, Lohbauer U. Bonding performance of universal adhesives in different etching modes. J Dent. 2014;42;42(7):800-7. doi: 10.1016/j. jdent.2014.04.012.

22. Muñoz MA, Luque-Martinez I, Malaquias P, Hass V, Reis A, Campanha $\mathrm{NH}$, et al. In vitro longevity of bonding properties of universal adhesives to dentin. Oper Dent. 2015;40(3):282-92. doi: 10.2341/14-055-L.

23. Perdigão J, Kose C, Mena-Serrano AP, De Paula EA, Tay LY, Reis A, et al. A new universal simplified adhesive: 
18-month clinical evaluation. Oper Dent. 2014;39(2):11327. doi: 10.2341/13-045-C.

24. Kawazu M, Takamizawa T, Hirokane E, Tsujimoto A, Tamura T, Barkmeier WW, et al. Comparison of dentin bond durability of a universal adhesive and two etch-andrinse adhesive systems. Clin Oral Investig. 2020;24(8):288997. doi: 10.1007/s00784-019-03153-y.

25. Reis A, Leite TM, Matte K, Michels R, Amaral RC, Geraldeli $S$, et al. Improving clinical retention of one-step self-etching adhesive systems with an additional hydrophobic adhesive layer. J Am Dent Assoc. 2009;140(7):877-85. doi: 10.14219/ jada.archive.2009.0281.

26. Waidyasekera K, Nikaido T, Weerasinghe DS, Ichinose S, Tagami J. Reinforcement of dentin in self-etch adhesive technology: a new concept. J Dent. 2009;37(8):604-9. doi: 10.1016/j.jdent.2009.03.021.

27. Perdigão J, Sezinando A, Monteiro PC. Laboratory bonding ability of a multi-purpose dentin adhesive. Am J Dent. 2012;25(3):153-8.

28. Yoshioka M, Yoshida Y, Inoue S, Lambrechts P, Vanherle G, Nomura Y, et al. Adhesion/decalcification mechanisms of acid interactions with human hard tissues. J Biomed Mater Res. 2002;59(1):56-62. doi: 10.1002/jbm.1216.

29. Pashley DH, Tay FR, Breschi L, Tjäderhane L, Carvalho RM, Carrilho M, et al. State of the art etch-and-rinse adhesives. Dent Mater. 2011;27(1):1-16. doi: 10.1016/j. dental.2010.10.016.

30. Matsumoto K, Hossain M, Tsuzuki N, Yamada Y. Morphological and compositional changes of human dentin after Er:YAG laser irradiation. J Oral Laser Appl. 2003;3(1):15-20.

31. Hossain M, Nakamura Y, Murakami Y, Yamada Y, Matsumoto K. A comparative study on compositional changes and Knoop hardness measurement of the cavity floor prepared by Er:YAG laser irradiation and mechanical bur cavity. J Clin Laser Med Surg. 2003;21(1):29-33. doi: 10.1089/10445470360516716.

32. Trevelin LT, Silva BTF, Arana-Chavez VE, Matos AB. Impact of Er:YAG laser pulse duration on ultra-structure of dentin collagen fibrils. Lasers Dent Sci. 2018;2(2):73-9. doi: 10.1007/s41547-017-0020-1.

33. Cardoso MV, Coutinho E, Ermis RB, Poitevin A, Van Landuyt K, De Munck J, et al. Influence of Er,Cr:YSGG laser treatment on the microtensile bond strength of adhesives to dentin. J Adhes Dent. 2008;10(1):25-33. doi: 10.3290/j.jad.a13088.

34. Moretto SG, Azambuja N Jr, Arana-Chavez VE, Reis AF, Giannini M, Eduardo CP, De Freitas PM. Effects of ultramorphological changes on adhesion to lased dentinscanning electron microscopy and transmission electron microscopy analysis. Microsc Res Tech. 2011;74(8):720-6. doi: 10.1002/jemt.20949.

35. Kameyama A, Kawada E, Takizawa M, Oda Y, Hirai Y. Influence of different acid conditioners on the tensile bond strength of 4-META/MMA-TBB resin to Er:YAG laserirradiated bovine dentin. J Adhes Dent. 2000;2(4):297-304.
36. Esteves-Oliveira M, Zezell DM, Apel C, Turbino ML, Aranha AC, Eduardo $\mathrm{CP}$, et al. Bond strength of selfetching primer to bur cut, Er,Cr:YSGG, and Er:YAG lased dental surfaces. Photomed Laser Surg. 2007;25(5):373-80. doi: 10.1089/pho.2007.2044.

37. de Oliveira MT, Arrais CA, Aranha AC, de Paula Eduardo C, Miyake K, Rueggeberg FA, et al. Micromorphology of resin-dentin interfaces using one-bottle etch \& rinse and self-etching adhesive systems on laser-treated dentin surfaces: a confocal laser scanning microscope analysis. Lasers Surg Med. 2010;42(7):662-70. doi: 10.1002/ lsm. 20945.

38. Giachetti L, Scaminaci Russo D, Scarpelli F, Vitale M. SEM analysis of dentin treated with the Er:YAG laser: a pilot study of the consequences resulting from laser use on adhesion mechanisms. J Clin Laser Med Surg. 2004;22(1):35-41. doi: $10.1089 / 104454704773660958$.

39. Moszner N, Salz U, Zimmermann J. Chemical aspects of self-etching enamel-dentin adhesives: a systematic review. Dent Mater. 2005;21(10):895-910. doi: 10.1016/j. dental.2005.05.001.

40. Koliniotou-Koumpia E, Kouros P, Zafiriadis L, Koumpia E, Dionysopoulos P, Karagiannis V. Bonding of adhesives to Er:YAG laser-treated dentin. Eur J Dent. 2012;6(1):16-23. doi: 10.1055/s-0039-1698926.

41. Ferreira LS, Apel C, Francci C, Simoes A, Eduardo CP, Gutknecht N. Influence of etching time on bond strength in dentin irradiated with erbium lasers. Lasers Med Sci. 2010;25(6):849-54. doi: 10.1007/s10103-009-0715-y.

42. Ramos AC, Esteves-Oliveira M, Arana-Chavez VE, de Paula Eduardo C. Adhesives bonded to erbium:yttriumaluminum-garnet laser-irradiated dentin: transmission electron microscopy, scanning electron microscopy and tensile bond strength analyses. Lasers Med Sci. 2010;25(2):181-9. doi: 10.1007/s10103-008-0600-0.

43. Saraceni CH, Liberti E, Navarro RS, Cassoni A, Kodama R, Oda M. Er:YAG-laser and sodium hypochlorite influence on bond to dentin. Microsc Res Tech. 2013;76(1):72-8. doi: 10.1002/jemt.22138.

44. Hashimoto M, Nagano F, Endo K, Ohno H. A review: Biodegradation of resin-dentin bonds. Jpn Dent Sci Rev. 2011;47(1):5-12. doi: 10.1016/j.jdsr.2010.02.001.

45. Torres CRG, de Araujo MAM, Teixeira SC, de Araujo RM, Huhtala MFR. Cavity preparation with Er:YAG laser or rotary instruments: investigation of the composite resin restorations interface. World J Dent. 2011;2(2):83-7. doi: 10.5005/jp-journals-10015-1061.

46. Guven Y, Aktoren O. Shear bond strength and ultrastructural interface analysis of different adhesive systems to Er:YAG laser-prepared dentin. Lasers Med Sci. 2015;30(2):769-78. doi: 10.1007/s10103-013-1424-0.

47. Costa DM, Somacal DC, Borges GA, Spohr AM. Bond capability of universal adhesive systems to dentin in self-etch mode after short-term storage and cyclic loading. Open Dent J. 2017;11:276-83. doi: 10.2174/1874210601711010276. 